\title{
Pourquoi disons-nous une chose et faisons-nous le contraire?
}

\section{Jean Martin}

Dr med., membre de la rédaction et ancien membre de la Commission nationale d'éthique

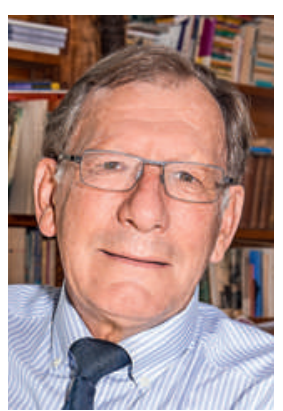

De plus en plus d'entre nous sont sensibilisés au fait que l'usage des ressources non renouvelables et ses effets sur le climat sont des enjeux vitaux. L'accord de Paris de décembre 2015 a été une avancée importante dans le bon sens et, en avril dernier, 175 Etats ont confirmé leur engagement à New York. Pourtant, les mêmes gouvernements ne font pas mine (si ce n'est peut-être au Bhoutan!) de réfléchir sérieusement, dans la recherche du bien-être de leurs concitoyens, à un vrai changement de paradigme; ils ne voient de salut que dans une forte croissance, «à l'ancienne».

Avec Susana Jourdan, Jacques Mirenowicz est le créateur de l'excellent La Revue Durable. Il parlait récemment à l'Université de Lausanne dans le cadre d'une série de conférences «Quelles alternatives pour notre monde?». La diplomatie climatique, dit-il, a eu un beau succès à Paris. Mais, alors même qu'elle fait partie de l'action gouvernementale, chacune dans son pays, elle reste marginalisée par les pressions qu'exercent les «super-tankers» que sont, politiquement, d'autres ministères (de l'économie, des finances). Certains parlent de schizophrénie. En tout cas, il s'agit d'incohérence grave dans l'action publique: nous disons une chose et en faisons une autre. Mirenowicz rappelle l'épisode fameux du Juge Frankfurter, de la Cour suprême des Etats-Unis, répondant en 1943 à Jan Karski, diplomate polonais accouru à l'Ouest faire connaitre l'élimination des juifs par les nazis: «Je dois être tout à fait franc, je suis incapable de vous croire»; critiqué plus tard, il a expliqué: «Je n’ai pas dit que ce jeune homme mentait, mais que je ne pouvais le croire.» Mutatis mutandis, c'est nous aujourd'hui: chaque jour, les faits signalent qu'il y a un problème formidable mais nous ne convertissons pas notre compréhension en action [1]. Bien sûr, c'est d'abord aux politiques de prendre des décisions, mais chacun peut s'engager et les pousser à le faire.

Dans ce sens, La Revue Durable crée «Artisans de la transition», une association qui entend «multiplier les lieux où il est possible, là où on se trouve, de se joindre à la transition" vers une société dont l'empreinte écologique soit (beaucoup) réduite. Par des démarches individuelles ou collectives/coopératives, dans la production de nourriture (devenir des locavores - ceux qui mangent local) et la non-dépendance aux énergies fossiles notamment.
Comment ne pas voir que, à défaut de mutation(s) rapide(s), les choses ne pourront qu'aller mal, de plus en plus mal. Comment Donald Trump, s'il devient président des Etats-Unis, réagira-t-il si on lui parle de diminuer les gaspillages insensés et de freiner la croissance? Poser la question, c'est y répondre: $M$. Trump ne négociera pas, il ne cherchera pas de solutions où chacun fait sa part (correspondant à sa responsabilité); il fera la guerre, sous une forme ou l'autre, économique, électronique, militaire.

Dans son exposé, Mirenowicz a fait référence aux 24 graphiques connus sous le titre Great Acceleration [2]; croissances exponentielles en termes de démographie mondiale, consommations d'eau et d'énergie, gaz à effet de serre, acidification des océans, dégradation de la biosphère, diminution de la forêt tropicale, nombre de voitures produites etc. Ce sont là des «hard data» illustrant la croissance incontrôlée des productions et consommations - c'est sur cette base qu'on parle d'ère anthropocène. Des «hard data» qui interdisent d'imaginer qu'il n'y a pas de problème et que everything is going to be allright - comme le font encore certains beaux esprits qui "savent mieux».

Quoique très inquiet, il me semble entrevoir une «accélération" porteuse d'espoir, la sensibilisation des millennials (nés entre 1985 et 2000): la conférence de Mirenowicz avait lieu en fin de journée le mercredi précédant, le congé de l'Ascension, par un temps radieux... pourtant une centaine d'étudiants (et quelques anciens) s'étaient déplacés. Anecdotique, mais signe que ce ne sont pas seulement des alarmistes marginaux qui veulent réfléchir à un avenir vivable. C'est aussi le message du film Demain, qui rencontre un grand succès. La jeune génération réalise que, sans transition vers un nouveau paradigme, la "patate chaude» que nous leur passons sera source de difficultés et drames dont nous peinons aujourd'hui à imaginer l'ampleur.

\section{Références}

1 George Marshall, scientifique britannique, en débat dans Don't even think about it - Why our brains are wired to ignore climate change (Bloomsbury, London, 2014), dont plusieurs chapitres sont traduits in La Revue Durable, $\mathrm{n}^{\circ}$ 56, janvier-mars 2016, p. 16-61.

2 https://www.google.ch/search?q=great+acceleration\&newwindow 